\title{
Penetration of Chitosan into the Single Walled Armchair Carbon Nanotubes: Atomic Scale Insight
}

\author{
Jamoliddin Razzokov ${ }^{1,2,3,4, * \mathbb{D}}$, Parthiban Marimuthu ${ }^{5, * \mathbb{D}}$, Kamoladdin Saidov ${ }^{1}$, Olim Ruzimuradov ${ }^{6,7}$ and \\ Shavkat Mamatkulov ${ }^{1}$ (D)
}

check for updates

Citation: Razzokov, J.; Saidov, K.; Ruzimuradov, O.; Mamatkulov, S Penetration of Chitosan into the Single Walled Armchair Carbon Nanotubes: Atomic Scale Insight. Crystals 2021, 11, 1174. https:// doi.org/10.3390/cryst11101174

Academic Editor: Paolo Restuccia

Received: 23 August 2021

Accepted: 18 September 2021

Published: 27 September 2021

Publisher's Note: MDPI stays neutral with regard to jurisdictional claims in published maps and institutional affiliations.

Copyright: (c) 2021 by the authors. Licensee MDPI, Basel, Switzerland. This article is an open access article distributed under the terms and conditions of the Creative Commons Attribution (CC BY) license (https:// creativecommons.org/licenses/by/ $4.0 /)$.
1 Institute of Material Sciences, Academy of Sciences, Chingiz Aytmatov 2b, Tashkent 100084, Uzbekistan; k.saidov@skku.edu (K.S.); mi-shavkat@yandex.ru (S.M.)

2 Department of Physics and Chemistry, Tashkent Institute of Irrigation and Agricultural Mechanization Engineers, Kori Niyoziy 39, Tashkent 100000, Uzbekistan

3 Department of Physics, National University of Uzbekistan, Universitet 4, Tashkent 100174, Uzbekistan

4 College of Engineering, Akfa University, Little Ring Road 17, Tashkent 100095, Uzbekistan

5 Pharmaceutical Science Laboratory and Structural Bioinformatics Laboratory, Faculty of Science and Engineering, Åbo Akademi University, FI-20520 Turku, Finland

6 Department of Natural and Mathematic Sciences, Turin Polytechnic University in Tashkent, Little Ring Road 17, Tashkent 100095, Uzbekistan; o.ruzimuradov@polito.uz

7 Department of Chemistry, National University of Uzbekistan, Universitet 4, Tashkent 100174, Uzbekistan

* Correspondence: j.razzokov@imssolar.uz (J.R.); parthiban.marimuthu@abo.fi (P.M.); Tel.: +998-90-116-2320 (J.R.)

Abstract: (1) Background: Currently, nanomaterials have been broadly used in various applications including engineering, medicine and biology. One of the carbon allotropes such as carbon nanotubes (CNTs) implemented for fabrication of nanocomposite materials due to the hypersensitivity. The combined design of nanomaterial with chitosan (CS) and CNT expands the field of exploitation from biosensing and tissue engineering to water desalination. Therefore, the penetration of CS into CNT provides a valuable insight into the interactions between CS and CNT. (2) Methods: We performed molecular dynamics simulations, applying the umbrella sampling method, in order to calculate the potential mean force between CS and CNT. (3) Results: The estimated penetration free energies showed that CS is favorable to the penetration into CNT cavities. However, the penetration nature differs depending on the CNT's architecture. (4) Conclusions: Our finding revealed the CS penetration process into CNT with nanoscale precision. The investigation results assist in a better understanding of the nanocomposite materials based on CS-CNT.

Keywords: carbon nanotube; chitosan; functional modification; molecular dynamics; penetration; free energy profile

\section{Introduction}

Carbon nanotubes (CNTs) have been extensively studied due to their unique mechanical strength, electrical conductivity and thermal stability [1,2]. These properties have gained great attention from the scientific community, including academia and industries [3-5]. In recent years, the application of CNT-based materials for biomedical purposes such as drug delivery, antimicrobial activity, tissue engineering and biosensors also significantly increased [6-11]. Despite the promising features of CNT, the latter itself exhibits cytotoxicity towards the various cell lines [12,13]. Thus, the high toxicity of CNT demands a careful approach in order to design CNT-based nanomaterials. In order to decrease the harmful effects, specifically the cytotoxicity, of these nanomaterials, the modifications or a combined use of CNTs by biopolymers might be an alternative solution [14,15]. Biopolymers such as chitosan (CS) maintains biocompatibility due to its unique biophysical and biochemical properties [16]. 
$\mathrm{CS}$ is a linear polysaccharide, i.e., $\beta$ - $(1 \rightarrow 4)$-linked 2 -acetamido-2-deoxy- $\beta$-d-glucopyr anose and 2-amino-2-deoxy- $\beta$-d-glucopyranose, which can be derived by deacetylation of chitin [17]. The human body is able to degrade CS into amino sugars, which become a nontoxic byproduct to the organism. Therefore, CS is quite suitable in biomedical applications $[18,19]$. In previous studies, a CNT-CS nanomaterial was obtained by depositing CS on the surface of the CNT [20]. The SEM images showed that the CNT structure was not compromised after covering CNT with the cross-linked CSs and it can be used for various biological purposes. Multi-walled CNT (MWCNT) was fabricated in combination with CS and $\beta$-Glycerophosphate (i.e., scaffold) with an improved electrical conductivity and mechanical strength [21]. This kind of scaffold might be employed for bone tissue repair and regeneration with the desired mechanical properties. In the literature [8], an antimicrobial porous CNT-CS hydrogel was developed. The hydrogel was found to be effective against the Staphylococcus aureus, Escherichia coli and Candida tropicalis. The controlled drug delivery was achieved by MWCNT-CS, incorporated with the thermosensitive hydrogel [22]. The photothermal irradiation disrupts the hydrogel and consequently leads to the release of the entrapped drug in CNT. Moreover, the special drug-loaded CNT-based systems, which are designed to release encapsulated drugs, have been investigated via molecular level simulations [23-25]. The above-mentioned investigations are evidence of the importance of CNT-CS-based nanomaterials in biomedical applications. Despite the advances in the field, the molecular-level interactions between CNT and CS have not been studied in detail yet. Mainly, the adsorption processes of CS on the surface of CNT have been investigated by computer simulations [26-30]. However, the penetration of CS into CNTs with the atomic scale resolution is still unknown.

In this study, we perform umbrella sampling (US) molecular dynamic (MD) [31] simulations to calculate the free energy profiles (FEPs) of chitosan penetrated into the armchair CNTs. We consider three types of armchair nanotubes in our simulations, which differ by their diameters. Specifically, we compare the calculated FEPs of chitosan penetrated into the CNTs in order to elucidate the penetration capability of CS into the CNT cavity.

\section{Materials and Methods}

\subsection{Molecular Dynamics Simulations}

The non-reactive MD simulations were performed by means of GROMACS-5.1 (developed by University of Groningen, Royal Institute of Technology and Uppsala University) program package [32]. The armchair nanotubes 3D structures was created with nanotube builder which is one of the options of VMD software (version 1.9.2, University of Illinois at Urbana-Champaign, Champaign, IL, USA) (see Figure 1a,b) [33]. The three types of CNTs were created with the following parameters: CNT1(9:9), CNT2(11:11) and CNT3(13:13). In our simulations, we used three different model systems MOD1, MOD2 and MOD3, which contains CNT1, CNT2 and CNT3, respectively. The length of the all CNT's is the same, i.e., $3.26 \mathrm{~nm}$, and the radii of the latter differs one to another. The hydrogen atoms were added to the terminal ends of the CNT using a Jmol software [34]. 
a)

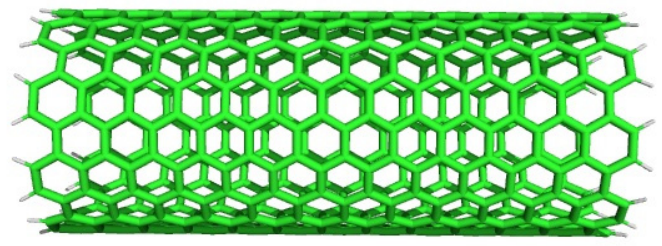

c)

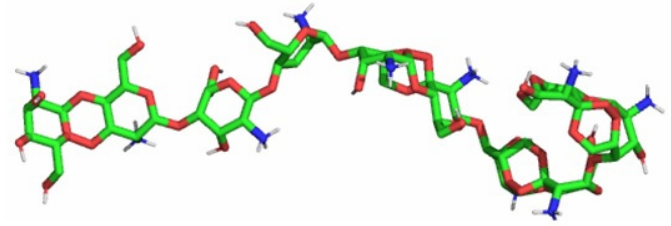

b)

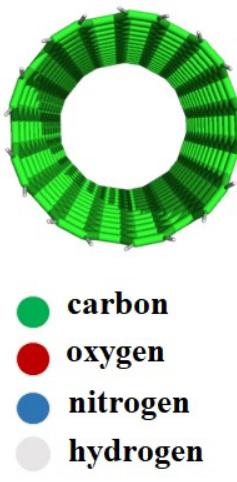

Figure 1. Armchair CNT: (a) a side view and (b) a front view. (c) Chitosan polymer with eight repeat unit.

The opening of CNT can be achieved with H-molecules at relatively low temperatures by assisting various transitional metals such as $\mathrm{Co}$, Ni or $\mathrm{Cu}[35,36]$. These catalysts break $\mathrm{H}-\mathrm{H}$ and $\mathrm{C}-\mathrm{C}$ bonds, and consequently hydrogen diffuses to a $\mathrm{C}$ atom to create a terminal $\mathrm{C}-\mathrm{H}$ bond in CNT. The QM/MM and DFT calculations showed forming C-H bonds in the terminal ends of CNT $[37,38]$. Therefore, we also used H-capped CNT in our model systems.

The all-atom OPLS-AA force field was used to carry out MD simulations [32,39]. The non-bonded interaction parameters and the partial charges were obtained from the literature only for the case of CS [27]. The OPLS-AA force field parameters were applied for CNT, which is available in the database of GROMACS. In order to create model systems, we placed CNT and CS in a tetragonal box with the adequate size, as illustrated in Figure 2, and the $1.0 \mathrm{~nm}$ buffer interval was set up between CNT/CS and the boundary of the simulation box. The current dimension was chosen in order to escape long distance interactions between the periodic images of molecules. The space between the closest atoms of CNT and CS is $1.2 \mathrm{~nm}$. In other words, they do not interact during the equilibration and production MD simulations. The reason for this is the mentioned distance is larger than the cut-off radius which was $1.0 \mathrm{~nm}$ as applied in our simulations.

a)

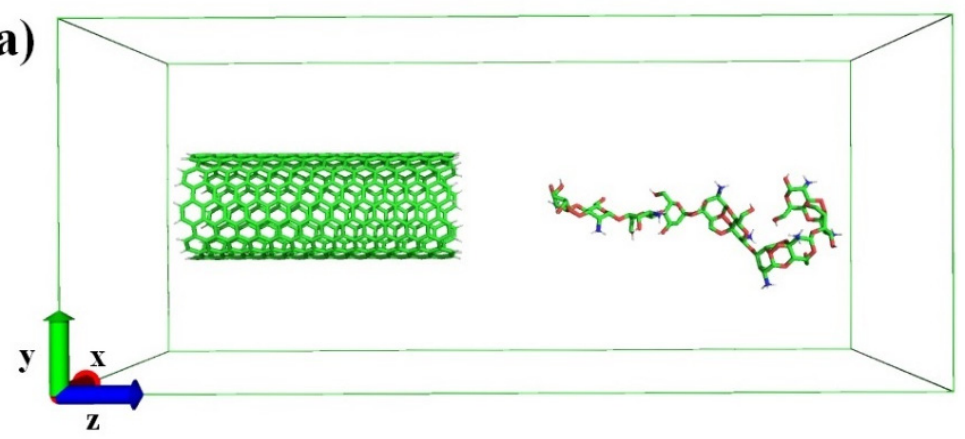

b)

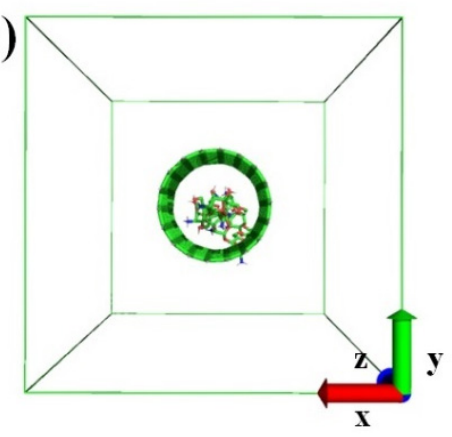

Figure 2. Armchair CNT and CS in a tetragonal box: (a) a side view and (b) a front view. Note that, for the sake of clarity, the water molecules were eliminated in the simulation box.

The simulation box is filled with the SPC water model [40]. Furthermore, energy minimization runs are performed by applying a steepest descent algorithm [41]. Note that, to fix the positions of CNT, four atoms in terminal ends and one atom of CS, which is close to $\mathrm{CNT}$, were frozen in the $\mathrm{X}, \mathrm{Y}$ and $\mathrm{Z}$ direction. Next, short 100 ps equilibration be carried out using an NVT ensemble (i.e., a system with constant number of particles $\mathrm{N}$, volume $\mathrm{V}$ and temperature T) followed by 20 ns productions run employing an NPT ensemble (i.e., a system with constant number of particles $\mathrm{N}$, pressure $\mathrm{P}$ and temperature $\mathrm{T}$ ). During the production run, $300 \mathrm{~K}$ temperature and 1 bar of pressure was maintained. The velocityrescaling thermostat and isotropic Parrinello-Rahman barostat were employed with a coupling constant and a compressibility of $2 \mathrm{ps}$ and $4.5 \times 10^{-5} \mathrm{bar}^{-1}$, respectively [42,43]. 
The long range electrostatic interactions were treated by the particle mesh Ewald (PME) method [44]. The final structure after the production run was extracted from the last snapshot of the simulation trajectory. The obtained model system was further used for the US simulations [31]. The same procedures were implemented for other model systems, such as MOD2 and MOD3.

\subsection{Umbrella Sampling Simulations}

The equilibrated model systems were employed to perform pulling simulations. As a reaction to coordinate the center of mass (COM) of the CNT, one of the oxygen atoms of the CS was set. The external perturbation was applied along the $Z$-axis on an oxygen atom of CS, while the COM of CNT was restrained. As a result, the external force caused a displacement of the CS towards the CNT and it enabled a calculation of the energy along the reaction coordinate. During the pulling simulation, $1000 \mathrm{~kJ} /\left(\mathrm{mol}^{*} \mathrm{~nm}^{2}\right)$ spring constant with a pulling rate of $0.01 \mathrm{~nm} / \mathrm{ps}$ was specified. The current simulation lasted for 300 ps. Furthermore, 30 windows were extracted from the trajectory file by calculating the distance between the COM, each separated by $0.1 \mathrm{~nm}$ along the Z-axis. Subsequently, each individual window was run through another $10 \mathrm{~ns}$ of US simulations. Afterwards, the obtained output files were used to calculate the potential mean force by making use of the weighted histogram analysis method (WHAM) [45]. The umbrella histograms were calculated for the case of MOD1 system (see Figure A1 in Appendix A). The degree of overlapping positions of these histograms serves as a hallmark for reliable sampling of US simulations. In total, 3 model systems $\times 30$ US $=90$ US simulations were performed to obtain the FEPs.

\section{Results and Discussion}

The production run was performed in order to obtain the equilibrated simulation box for further simulations. The equilibrated simulation box was used to perform a pulling simulation (see above). As is clear from Figure 3, the external force applied to CS relocates it along the Z-axis towards the CNT. Step-by-step CS enters into the CNT and the penetration process takes place until the distance between the reaction coordinates (e.g., COM) reaches zero (see Figure 3c,d). Subsequently, 30 windows were extracted from the simulation trajectory and were used to carry out $10 \mathrm{~ns}$ US simulations for each individual window by applying the production run conditions with a zero pulling rate.

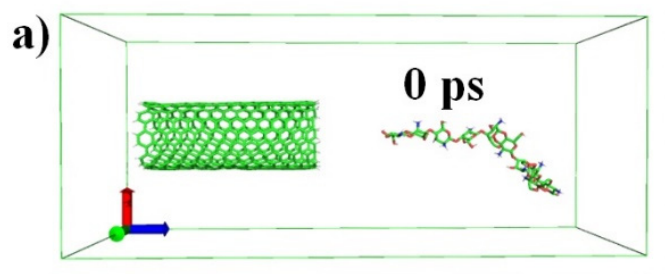

c)

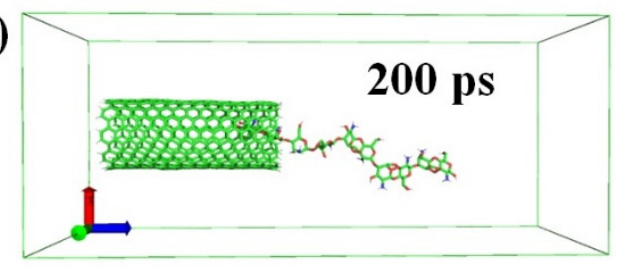

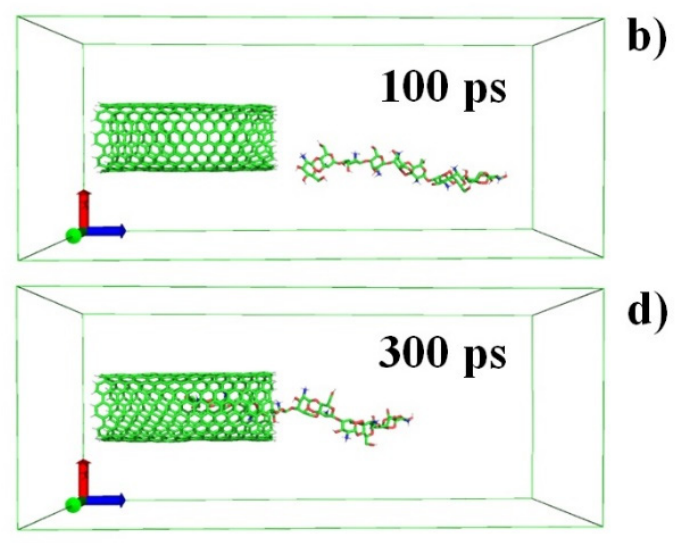

b)

d)

Figure 3. Snapshots extracted from the pulling simulation for the MOD1 system. (a) The initial 0 ps, (b) 100 ps, (c) 200 ps and (d) the final $300 \mathrm{ps}$ frames obtained by analysis of simulation trajectory.

The final simulation system, which is CS, was sufficiently embedded into the CNT and further analyzed (see Figure 3d). Interestingly, we found that the part of CS exposed to water was bended and adsorbed on to the surface of CNT1 during the US simulations (cf. Figures 3d and 4a). Moreover, the penetrated part of the CS was almost linear in 
CNT1 (see Figure 4a). The position of CS in CNT2 changes and most of the part of the CS escapes from the aqueous media by entering into CNT2 (see Figure 4b). In contrast, CS was fully penetrated into CNT3 in the MOD3 system by twirling and rotating its structure (see Figure 4c). The calculated radius of gyration of CS in the MOD3 system shows a comparatively smaller value than MOD1 and MOD2 systems (see Table A1 in Appendix A). This means that the tightest packing of CS occurs inside the cavity of CNT in the MOD3 system. Apparently, if the radii of CNT increases, the chance of a full penetration of CS into CNTs also enhances. The calculated average value of $\mathbf{E}_{\mathbf{C S}} \mathbf{C N T}$ non-bonded interaction energy between CS and CNT rises upon an increase of the radii of CNT (see Table 1). In these cases, the solvent accessible surface area of CS to water decreases in MOD2 and in MOD3 in comparison with MOD1 (see Table A1 in Appendix A). The calculated average values of E $_{\text {CS_water }}$ non-bonded interaction energy between CS and water drops in model systems which include CNT2 and CNT3 (see Table 1).

a)
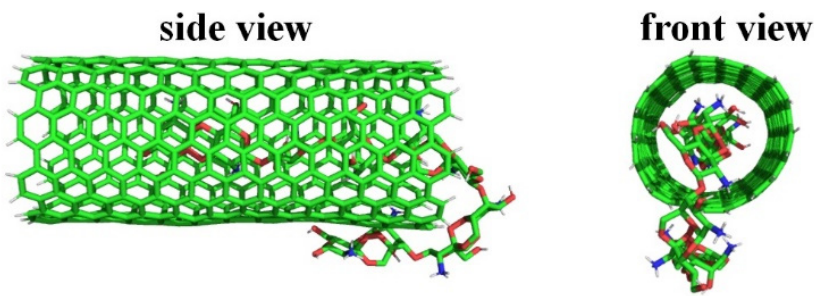

b)
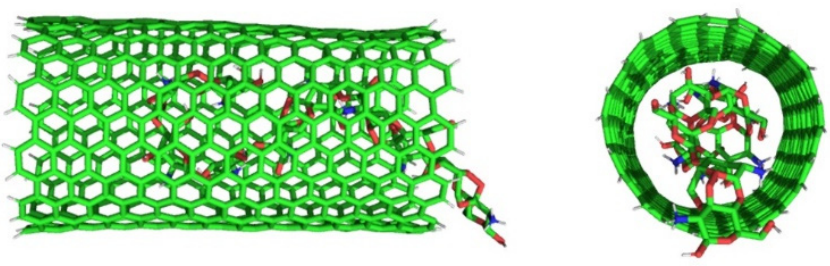

c)
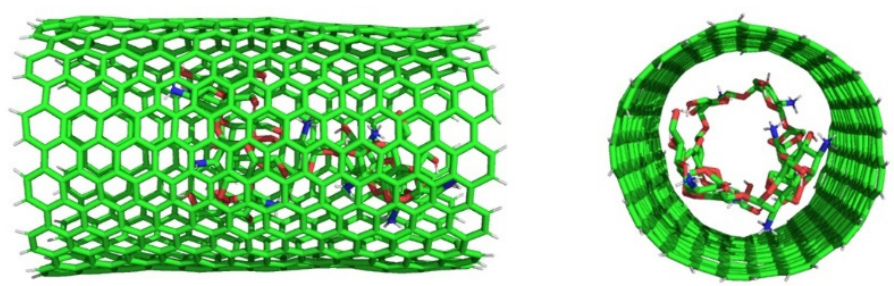

Figure 4. The final snapshots of CS and CNT extracted from US simulations: (a) MOD1, (b) MOD2 and (c) MOD3.

Table 1. The calculated non-bonded interaction energy between CS and CNT and CS and water.

\begin{tabular}{ccc}
\hline Model System & E $_{\text {CS_CNT }}(\mathbf{k J} / \mathbf{m o l})$ & E $_{\text {CS_water }}(\mathbf{k J} / \mathbf{m o l})$ \\
\hline MOD1 & $-432.42 \pm 12.51$ & $-177.08 \pm 12.02$ \\
MOD2 & $-452.64 \pm 16.44$ & $-104.05 \pm 13.97$ \\
MOD3 & $-484.05 \pm 12.11$ & $-68.94 \pm 12.42$ \\
\hline
\end{tabular}

In order to quantitatively estimate the interaction energy between CS and CNTs, we carried out US simulations to identify the penetration free energy of CS into CNTs. The penetration FEPs help us to draw a conclusion of the penetration capability of CS into CNTs. Figure 5 exhibits the FEPs of CS pulled towards the COM of CNTs. Note that the difference between the maximum and minimum FEP gives the penetration free energy. Indeed, there is no interaction energy between CS and CNTs in the initial stage of the US simulations (see Figure 5). It is clear that FEPs start to decrease as CS enters into the interaction range of CNTs. Based on the graph, the calculated penetration-free energies of CS are found to be $-201.87 \pm$ $11.41,-161.13 \pm 13.10$ and $-127.93 \pm 5.13 \mathrm{~kJ} / \mathrm{mol}$ for MOD1, MOD2 and MOD3 systems, 
respectively. Apparently, the penetration free energy of CS in the MOD1 system was lowest. This means that the partial penetration of CS into CNT1 and adsorption of remained part of CS on the surface of CNT1 shows the most stable state of CS. The penetration free energy also showed negative values in MOD2 and MOD3 systems in comparison with the MOD1 system. The negative values of penetration free energy in all three systems indicate that in aqueous media, CS favorably permeates into CNTs.

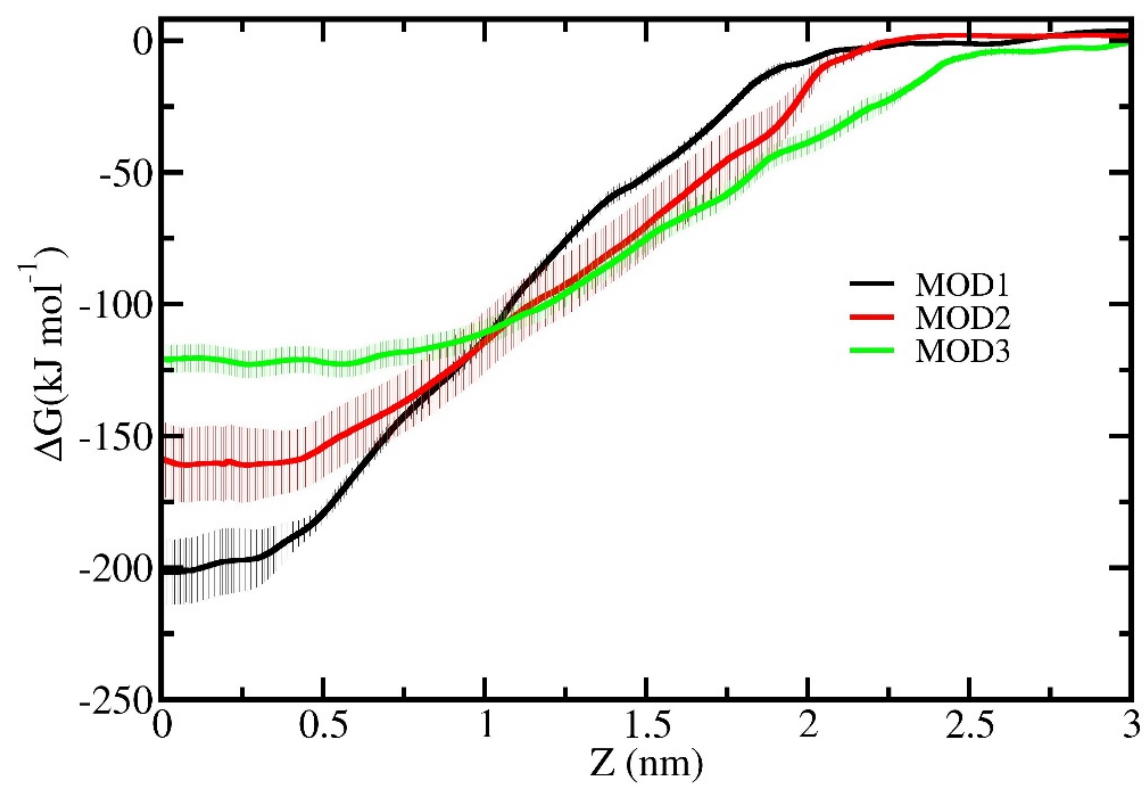

Figure 5. FEPs of CS in a MOD1, MOD2 and MOD3 system. The pale color shows the error bar associated with the sampling.

\section{Conclusions}

We studied the penetration capability of CS in three different kinds of CNTs employed in US MD simulations. The calculated FEP results indicate that CS partial penetration into CNT1, and the adsorption which remained partly on the surface of the latter, was the most energetically favorable position compared to other model systems. Interestingly, we observed that the CS penetration nature considerably changed in MOD2 and MOD3 systems. When the radii of CNT increased (e.g., in CNT2 and CNT3), CS moved further into the CNT. Specifically, CS rotated and maintained the spiral shape inside the CNT3 and the CS was entirely encapsulated in it.

Overall, the results of this study reveal the molecular level mechanisms of linear penetration and the full encapsulation process of CS into CNTs. The fully encapsulated CS into CNT3 can be employed to understand the targeted delivery system for biomedical purposes $[46,47]$. Moreover, these kinds of CS-CNT fabricated nanocomposites were also used for water desalination [48,49]. In general, our findings help to understand CS and CNT interactions in detail with the nanoscale resolution.

Author Contributions: Conceptualization, J.R. and S.M.; methodology, J.R.; software, J.R. and K.S.; validation, J.R. and K.S.; formal analysis, J.R. and K.S.; investigation, J.R., S.M. and O.R.; resources, P.M. and S.M.; data curation, J.R.; writing-original draft preparation, J.R.; writing-review and editing, J.R., P.M., K.S., O.R. and S.M.; visualization, K.S.; supervision, O.R. All authors have read and agreed to the published version of the manuscript.

Funding: This research was funded by Ministry of innovative development of the Republic of Uzbekistan, grant number FZ-2019-06066, FZ-2020092325 and MUK-2021-45. P.M. gratefully acknowledges the APC support by APC pool at $\AA$ AU.

Data Availability Statement: Data are contained within the article. 
Acknowledgments: P.M. gratefully acknowledges the use of the bioinformatics infrastructure facility supported by Biocenter Finland and the CSC-IT Center for Science (Project: 2000461) for the computational fa-cility; Jukka Lehtonen for the IT support; Mark Johnson (SBL) Åbo Akademi University for providing the lab support and Outi Salo-Ahen (Pharmacy) Åbo Akademi University.

Conflicts of Interest: The authors declare no conflict of interest.

\section{Appendix A}

\section{Umbrella histograms}

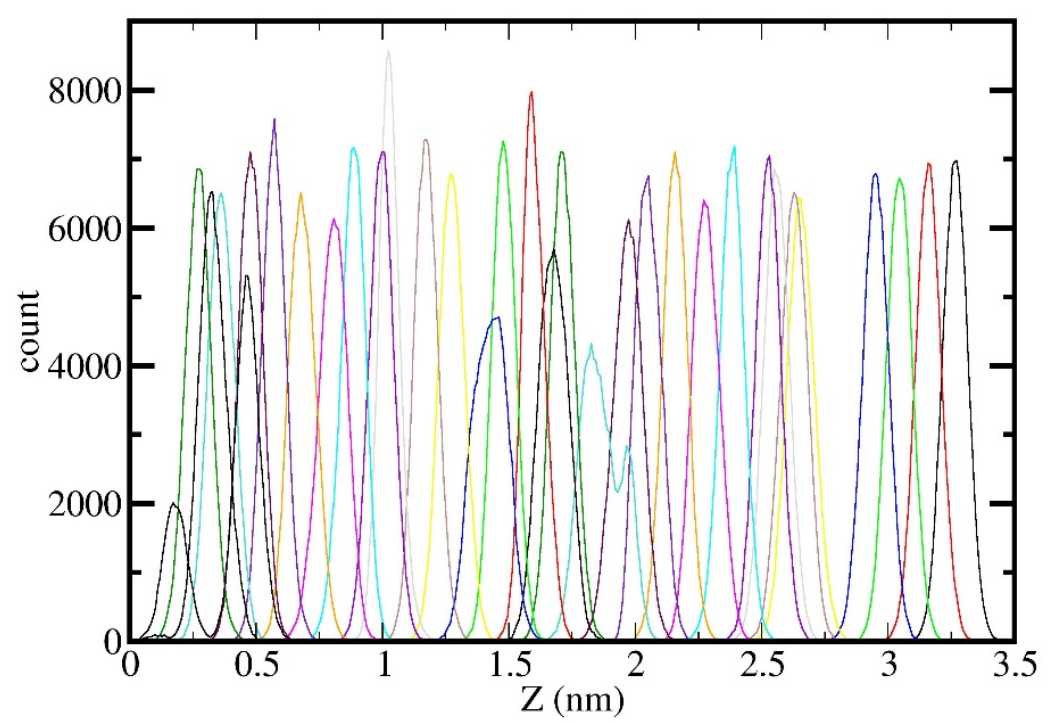

Figure A1. The histograms obtained for the case of MOD1 US simulations.

Table A1. The calculated solvent accessible surface area (SASA) and radius of gyration of CS for the case of MOD1, MOD2 and MOD3.

\begin{tabular}{ccc}
\hline Model System & SASA $\left(\mathbf{n m}^{\mathbf{2}}\right)$ & $\operatorname{Rg}(\mathbf{A})$ \\
\hline MOD1 & $19.32+0.36$ & $9.60 \pm 0.17$ \\
MOD2 & $16.99+0.43$ & $9.58 \pm 0.22$ \\
MOD3 & $16.43+0.77$ & $7.13 \pm 0.32$ \\
\hline
\end{tabular}

\section{References}

1. Dresselhaus, M.S.; Dresselhaus, G.; Eklund, P.C.; Rao, A.M. Carbon nanotubes. In The Physics of Fullerene-Based and Fullerene-Related Materials; Springer: Dordrecht, The Netherlands, 2000.

2. Khan, F.S.A.; Mubarak, N.; Khalid, M.; Khan, M.M.; Tan, Y.H.; Walvekar, R.; Abdullah, E.; Karri, R.R.; Rahman, M.E. Comprehensive review on carbon nanotubes embedded in different metal and polymer matrix: Fabrications and applications. Crit. Rev. Solid State Mater. Sci. 2021, 1-28. [CrossRef]

3. Peng, H.; Li, Q.; Chen, T. Industrial Applications of Carbon Nanotubes; William Andrew, Elsevier: Amsterdam, The Netherlands, 2016.

4. Mallakpour, S.; Azadi, E.; Hussain, C.M. Chitosan/carbon nanotube hybrids: Recent progress and achievements for industrial applications. New J. Chem. 2021, 45, 3756-3777. [CrossRef]

5. Kuralay, F.; Vural, T.; Bayram, C.; Denkbas, E.B.; Abaci, S.J.C.; Biointerfaces, S.B. Carbon nanotube-chitosan modified disposable pencil graphite electrode for Vitamin B12 analysis. Colloids Surf. B Biointerfaces 2011, 87, 18-22. [CrossRef] [PubMed]

6. Polizu, S.; Savadogo, O.; Poulin, P.; Yahia, L.H. Applications of carbon nanotubes-based biomaterials in biomedical nanotechnology. J. Nanosci. Nanotechnol. 2006, 6, 1883-1904. [CrossRef]

7. Kurbanoglu, S.; Ozkan, S.A. Electrochemical carbon based nanosensors: A promising tool in pharmaceutical and biomedical analysis. J. Pharm. Biomed. Anal. 2018, 147, 439-457. [CrossRef] [PubMed]

8. Venkatesan, J.; Jayakumar, R.; Mohandas, A.; Bhatnagar, I.; Kim, S.-K. Antimicrobial activity of chitosan-carbon nanotube hydrogels. Materials 2014, 7, 3946-3955. [CrossRef] 
9. Pyman, H.; Roshanfekr, H.; Ansari, S. DNA-based electrochemical biosensor using chitosan-carbon nanotubes composite film for biodetection of Pirazon. Eurasian Chem. Commun. 2020, 2, 213-225.

10. Parvaiz, M.S.; Shah, K.A.; Alrobei, H.; Dar, G.; Khanday, F.A.; Andrabi, S.M.A.; Hamid, R. Modeling and simulation of carbon nanotube amino-acid sensor: A first-principles study. Comput. Theor. Chem. 2021, 1204, 113402. [CrossRef]

11. Zhang, M.; Smith, A.; Gorski, W. Carbon nanotube-chitosan system for electrochemical sensing based on dehydrogenase enzymes. Anal. Chem. 2004, 76, 5045-5050. [CrossRef] [PubMed]

12. Cui, H.-F.; Vashist, S.K.; Al-Rubeaan, K.; Luong, J.H.; Sheu, F.-S. Interfacing carbon nanotubes with living mammalian cells and cytotoxicity issues. Chem. Res. Toxicol. 2010, 23, 1131-1147. [CrossRef]

13. Arora, S.; Kaur, H.; Kumar, R.; Kaur, R.; Rana, D.; Rayat, C.S.; Kaur, I.; Arora, S.K.; Bubber, P.; Bharadwaj, L.M. In vitro cytotoxicity of multiwalled and single-walled carbon nanotubes on human cell lines. Nanotub. Carbon Nanostruct. 2015, 23, 377-382. [CrossRef]

14. Adorinni, S.; Cringoli, M.C.; Perathoner, S.; Fornasiero, P.; Marchesan, S. Green Approaches to Carbon Nanostructure-Based Biomaterials. Appl. Sci. 2021, 11, 2490. [CrossRef]

15. Aoki, K.; Ogihara, N.; Tanaka, M.; Haniu, H.; Saito, N. Carbon nanotube-based biomaterials for orthopaedic applications. J. Mater. Chem. B 2020, 8, 9227-9238. [CrossRef] [PubMed]

16. Ghica, M.E.; Pauliukaite, R.; Fatibello-Filho, O.; Brett, C.M. Application of functionalised carbon nanotubes immobilised into chitosan films in amperometric enzyme biosensors. Sens. Actuators B Chem. 2009, 142, 308-315. [CrossRef]

17. Younes, I.; Rinaudo, M. Chitin and chitosan preparation from marine sources. Structure, properties and applications. Mar. Drugs 2015, 13, 1133-1174. [CrossRef]

18. Shukla, S.K.; Mishra, A.K.; Arotiba, O.A.; Mamba, B.B. Chitosan-based nanomaterials: A state-of-the-art review. Int. J. Biol. Macromol. 2013, 59, 46-58. [CrossRef]

19. Cheung, R.C.F.; Ng, T.B.; Wong, J.H.; Chan, W.Y. Chitosan: An update on potential biomedical and pharmaceutical applications. Mar. Drugs 2015, 13, 5156-5186. [CrossRef]

20. Liu, Y.; Tang, J.; Chen, X.; Xin, J.H. Decoration of carbon nanotubes with chitosan. Carbon 2005, 43, 3178-3180. [CrossRef]

21. Gholizadeh, S.; Moztarzadeh, F.; Haghighipour, N.; Ghazizadeh, L.; Baghbani, F.; Shokrgozar, M.A.; Allahyari, Z. Preparation and characterization of novel functionalized multiwalled carbon nanotubes/chitosan/ $\beta$-Glycerophosphate scaffolds for bone tissue engineering. Int. J. Biol. Macromol. 2017, 97, 365-372. [CrossRef]

22. Dong, X.; Wei, C.; Liang, J.; Liu, T.; Kong, D.; Lv, F. Thermosensitive hydrogel loaded with chitosan-carbon nanotubes for near infrared light triggered drug delivery. Colloids Surf. B Biointerfaces 2017, 154, 253-262. [CrossRef]

23. Wolski, P.; Nieszporek, K.; Panczyk, T. Multimodal, pH sensitive, and magnetically assisted carrier of doxorubicin designed and analyzed by means of computer simulations. Langmuir 2018, 34, 2543-2550. [CrossRef] [PubMed]

24. Wolski, P.; Nieszporek, K.; Panczyk, T. Cytosine-Rich DNA Fragments Covalently Bound to Carbon Nanotube as Factors Triggering Doxorubicin Release at Acidic pH. A Molecular Dynamics Study. Int. J. Mol. Sci. 2021, 22, 8466. [CrossRef]

25. Mejri, A.; Tangour, B.; Herlem, G.; Picaud, F. Confinement of the antitumoral drug cisplatin inside edge-functionalized carbon nanotubes and its release near lipid membrane. Eur. Phys. J. D 2021, 75, 1-10. [CrossRef]

26. Aztatzi-Pluma, D.; Castrejón-González, E.O.; Almendarez-Camarillo, A.; Alvarado, J.F.; Duran-Morales, Y. Study of the molecular interactions between functionalized carbon nanotubes and chitosan. J. Phys. Chem. C 2016, 120, 2371-2378. [CrossRef]

27. Azimov, J.; Mamatkulov, S.; Turaeva, N.; Oxengendler, B.; Rashidova, S.S. Computer modeling of chitosan adsorption on a carbon nanotube. J. Struct. Chem. 2012, 53, 829-834. [CrossRef]

28. Rungnim, C.; Rungrotmongkol, T.; Hannongbua, S.; Okumura, H. Modelling. Replica exchange molecular dynamics simulation of chitosan for drug delivery system based on carbon nanotube. J. Mol. Graph. Model. 2013, 39, 183-192. [CrossRef]

29. Yu, R.; Ran, M.; Wen, J.; Sun, W.; Chu, W.; Jiang, C.; He, Z. The effect of hydroxylation on CNT to form Chitosan-CNT composites: A DFT study. Appl. Surf. Sci. 2015, 359, 643-650. [CrossRef]

30. Ebrahimi, S.; Ghafoori-Tabrizi, K.; Rafii-Tabar, H. Multi-scale computational modelling of the mechanical behaviour of the chitosan biological polymer embedded with graphene and carbon nanotube. Comput. Mater. Sci. 2012, 53, 347-353. [CrossRef]

31. Kästner, J. Umbrella sampling. Comput. Mol. Sci. 2011, 1, 932-942. [CrossRef]

32. Van Der Spoel, D.; Lindahl, E.; Hess, B.; Groenhof, G.; Mark, A.E.; Berendsen, H.J. GROMACS: Fast, flexible, and free. J. Comput. Chem. 2005, 26, 1701-1718. [CrossRef]

33. Humphrey, W.; Dalke, A.; Schulten, K. VMD: Visual molecular dynamics. J. Mol. Graph. 1996, 14, 33-38. [CrossRef]

34. Herraez, A. Biomolecules in the computer: Jmol to the rescue. Biochem. Mol. Biol. Educ. 2006, 34, 255-261. [CrossRef] [PubMed]

35. Wang, J.; Ma, L.; Yuan, Q.; Zhu, L.; Ding, F. Transition-metal-catalyzed unzipping of single-walled carbon nanotubes into narrow graphene nanoribbons at low temperature. Angew. Chem. 2011, 123, 8191-8195. [CrossRef]

36. Kosynkin, D.V.; Lu, W.; Sinitskii, A.; Pera, G.; Sun, Z.; Tour, J.M. Highly conductive graphene nanoribbons by longitudinal splitting of carbon nanotubes using potassium vapor. ACS Nano 2011, 5, 968-974. [CrossRef]

37. Yang, F.H.; Lachawiec, A.J.; Yang, R.T. Adsorption of spillover hydrogen atoms on single-wall carbon nanotubes. J. Phys. Chem. B 2006, 110, 6236-6244. [CrossRef] [PubMed]

38. Khalilov, U.; Bogaerts, A.; Xu, B.; Kato, T.; Kaneko, T.; Neyts, E. How the alignment of adsorbed ortho H pairs determines the onset of selective carbon nanotube etching. Nanoscale 2017, 9, 1653-1661. [CrossRef]

39. Jorgensen, W.L.; Maxwell, D.S.; Tirado-Rives, J. Development and testing of the OPLS all-atom force field on conformational energetics and properties of organic liquids. J. Am. Chem. Soc. 1996, 118, 11225-11236. [CrossRef] 
40. Wu, Y.; Tepper, H.L.; Voth, G.A. Flexible simple point-charge water model with improved liquid-state properties. J. Chem. Phys. 2006, 124, 024503. [CrossRef]

41. Fliege, J.; Svaiter, B.F. Steepest descent methods for multicriteria optimization. Math. Methods Oper. Res. 2000, 51, 479-494. [CrossRef]

42. Parrinello, M.; Rahman, A. Polymorphic transitions in single crystals: A new molecular dynamics method. J. Appl. Phys. 1981, 52, 7182-7190. [CrossRef]

43. Bussi, G.; Donadio, D.; Parrinello, M. Canonical sampling through velocity rescaling. J. Chem. Phys. 2007, 126, 014101. [CrossRef] [PubMed]

44. Essmann, U.; Perera, L.; Berkowitz, M.L.; Darden, T.; Lee, H.; Pedersen, L.G. A smooth particle mesh Ewald method. J. Chem. Phys. 1995, 103, 8577-8593. [CrossRef]

45. Kumar, S.; Rosenberg, J.M.; Bouzida, D.; Swendsen, R.H.; Kollman, P.A. The weighted histogram analysis method for free-Energy calculations on biomolecules. I. The method. J. Comput. Chem. 1992, 13, 1011-1021. [CrossRef]

46. Rungnim, C.; Rungrotmongkol, T.; Poo-Arporn, R.P. pH-controlled doxorubicin anticancer loading and release from carbon nanotube noncovalently modified by chitosan: MD simulations. J. Mol. Graph. Model. 2016, 70, 70-76. [CrossRef]

47. Mohammadi, Z.A.; Aghamiri, S.F.; Zarrabi, A.; Talaie, M.R. A comparative study on non-covalent functionalization of carbon nanotubes by chitosan and its derivatives for delivery of doxorubicin. Chem. Phys. Lett. 2015, 642, 22-28. [CrossRef]

48. Alsuhybani, M.; Alshahrani, A.; Haidyrah, A.S. Synthesis, Characterization, and Evaluation of Evaporated Casting MWCNT/Chitosan Composite Membranes for Water Desalination. J. Chem. 2020, 2020, 5207680. [CrossRef]

49. Ma, C.-Y.; Huang, S.-C.; Chou, P.-H.; Den, W.; Hou, C.-H. Application of a multiwalled carbon nanotube-chitosan composite as an electrode in the electrosorption process for water purification. Chemosphere 2016, 146, 113-120. [CrossRef] 